IZA DP No. 5236

Efficient Redistribution: Comparing Basic Income with Unemployment Benefits

Felix FitzRoy

Jim Jin

October 2010 


\title{
Efficient Redistribution: Comparing Basic Income with Unemployment Benefits
}

\author{
Felix FitzRoy \\ University of St. Andrews \\ and IZA \\ Jim Jin \\ University of St. Andrews
}

Discussion Paper No. 5236

October 2010

\author{
IZA \\ P.O. Box 7240 \\ 53072 Bonn \\ Germany \\ Phone: +49-228-3894-0 \\ Fax: +49-228-3894-180 \\ E-mail: iza@iza.org
}

\begin{abstract}
Any opinions expressed here are those of the author(s) and not those of IZA. Research published in this series may include views on policy, but the institute itself takes no institutional policy positions.

The Institute for the Study of Labor (IZA) in Bonn is a local and virtual international research center and a place of communication between science, politics and business. IZA is an independent nonprofit organization supported by Deutsche Post Foundation. The center is associated with the University of Bonn and offers a stimulating research environment through its international network, workshops and conferences, data service, project support, research visits and doctoral program. IZA engages in (i) original and internationally competitive research in all fields of labor economics, (ii) development of policy concepts, and (iii) dissemination of research results and concepts to the interested public.
\end{abstract}

IZA Discussion Papers often represent preliminary work and are circulated to encourage discussion. Citation of such a paper should account for its provisional character. A revised version may be available directly from the author. 


\section{ABSTRACT \\ Efficient Redistribution: Comparing Basic Income with Unemployment Benefits*}

We compare two systems of income redistribution: unemployment benefits (UB) and basic income (BI). First, for a simple utility function, with both intensive and extensive margins, the unemployed are likely better off with pure $\mathrm{BI}$ than pure $\mathrm{UB}$, regardless of labour supply elasticity and wage distribution. Then we allow a general utility function and ignore intensive margins. For given unemployment, lowering $\mathrm{UB}$ and raising $\mathrm{BI}$ always benefits the unemployed, raises utilitarian welfare and benefits a poor majority. Reducing unemployment and UB simultaneously can benefit a majority of the employed as well as all unemployed, again for any wage distribution.

\section{NON-TECHNICAL SUMMARY}

We show that majority of the working population gains from switching from unemployment benefits to a universal basic income, with given unemployment and essentially any wage distribution, although the tax rate will increase.

JEL Classification: H20, D40

Keywords: income distribution, basic income, unemployment benefits

Corresponding author:

Felix FitzRoy

School of Economics and Finance

University of St Andrews

St Andrews KY16 9AL

Scotland

United Kingdom

E-mail: frf@st-andrews.ac.uk

\footnotetext{
* We thank seminar participants at St. Andrews, Tatiana Damjanovic, Alan Sutherland, and David Ulph for helpful comments and suggestions. The usual disclaimer applies.
} 


\section{Introduction`}

All developed economies use the tax system to redistribute income and alleviate poverty. These welfare systems are generally targeted at the most needy, and withdrawn or phased out quite rapidly for those in full-time work, or when earnings exceed some threshold. This means that less-qualified workers, particularly under generous European social security systems, may earn little more than they would receive as benefit income. The implicit, very high marginal tax rate faced by unskilled workers entering employment forms the 'poverty trap', which is widely seen as a substantial barrier to leaving dependency. On the other hand, if transfers to the unemployed are minimal, as in the UK and US, resulting downward pressure on wages does not prevent a rapid rise of unemployment and under-employment in recession and its aftermath (one in six of the US labour force in 2010), and ensures a much larger deprived share of the population than in Western Europe, with all its attendant social ills (Wilkinson and Pickett 2009).

A fundamental alternative to all kinds of conditional income support for the poor is a system of universal benefits, or an unconditional basic income for all citizens. This idea has attracted increasing academic and political attention (Atkinson 1995 and 2002; Offe 2008). Unusually, it has received support across a broad political spectrum, from conservatives to liberals and greens (Clark and Kavanagh 1996). Beside its economic benefits of alleviating the unemployment problem, basic income has broad implications for society, such as offering social security and freedom to all, enhancing equality and job satisfaction etc (for comprehensive discussion see Fitzpatrick 1999) ${ }^{1}$.

\footnotetext{
${ }^{1}$ A specialized journal "Basic Income Studies" is devoted to this topic.
} 
While removing the 'poverty trap', a basic income would of course have to be paid to the employed majority as well as to the unemployed, and in spite of many attractive properties has traditionally been considered to be too costly compared to the gains from additional unskilled employment. To maintain the welfare of the unemployed with a basic income at a similar level as conditional benefits would seem to require considerably higher taxes, which are likely to raise unemployment, and reduce most workers' welfare. Thus, while categorical unemployment benefits (UB) have existed for a long time in most western countries, a universal basic income or lump sum transfer (BI) still remains an untested and controversial, though increasingly popular, idea.

Optimal tax models often find that a universal transfer should be rapidly phased out by high marginal rates on low earners, followed by low marginal rates on middle and high incomes (Kaplow 2008). Such a largely regressive tax system mimics the effect of a categorical transfer to the unemployed which is withdrawn on entering employment, and imposes a high implicit marginal tax rate on low earners, who may not gain from working, and are caught in a 'poverty trap'. Furthermore, high initial marginal rates raise infra-marginal revenue from high earners, in contrast to politically more acceptable progressive systems. Optimal tax studies usually focus on individual labour supply, with an identical elasticity for all wage or skill levels, while neglecting the very low supply elasticity found empirically for full-time workers, and the most important extensive margin of participation. In their survey of tax theory and policy, Mankiw et al (2009, p.2) suggest that, "A flat tax, with a universal lump-sum transfer, could be close to optimal".

There has been little direct comparison of UB and BI in simple models with endogenous unemployment. Atkinson (1995) found that an exogenous group of disabled 
or sick, who were unable to supply any labour, could benefit from a categorical transfer, in addition to the basic income, but this approach does not include the extensive margin. Colombino et al (2010) recently carried out a systematic and detailed comparison of welfare and tax reform using disaggregated, microeconometric models and numerical simulations. Instead of focusing on the intensive margin, and assuming a constant elasticity of labour supply, they include both the intensive and extensive margins of the labour market, and incorporate empirical evidence that the elasticity of labour supply is close to zero for full time workers ${ }^{2}$. In this more realistic framework, they find that universal systems close to $\mathrm{BI}$, in combination with progressive taxes, may in fact dominate other welfare and tax reforms for some countries. Related work by Immervoll et al (2007), building on the optimal tax results of Saez (2002), finds that in-work benefits, which have become popular in recent years, tend to dominate. However such policies do not provide direct assistance to the unemployed.

The empirical evidence indeed shows that full-time labour supply is unresponsive to wages and taxes. Hours of work for full-time employees are generally determined by job-requirements, not individual preferences, and are highly correlated with earnings. The highest earners work such long hours as an integral part of their jobs, that they have little scope for increasing their labour supply. On the other hand, the participation decision for low-wage and part-time workers, many of them female, appears to be highly sensitive to financial incentives and alternatives to the labour market from available welfare benefits or at home (Colombino et al 2010; Immervoll et al 2007). For example, when Eissa and Liebman (1996) examined the impact of the U.S. Tax Reform Act 1986, which extends

\footnotetext{
${ }^{2}$ A separate issue is the ability of the rich to avoid tax by substituting into traditionally low-tax forms of income such as stock options (or emigrating), yielding relatively high tax revenue elasticity (Kaplow 2008).
} 
tax credit to single mothers, they found significant effects on labor participation, but no effect on the working hours of single mothers who were already in the labor force.

Chone and Laroque (2005 and 2008) have developed a model of the labour market with a distribution of ability, but only an extensive margin, assuming hours and earnings per unit of calendar time (week, month, or year) are given as part of the job 'package', and depend on ability or productivity. The only choice is thus whether to work, at a wage equal to individual productivity, or to rely on transfers. In the light of the empirical evidence summarized above, this approach represents a useful approximation and simplification for our purposes. Here we further simplify by assuming that only those with the lowest abilities prefer not to work, so for given tax and benefits there is always a marginal worker, such that those with lower ability or potential earnings choose not to work, and those with higher earnings prefer work. This is supported by the very low participation elasticity found for high earners (Blundell 1995), and accords with the strong positive correlation between non-pecuniary rewards and earnings found in surveys. In spite of compensating differentials between workers in the same skill-class, less qualified and lower paid workers generally have worse jobs and less job-satisfaction than those who earn more with better qualifications (Helliwell and Huang 2005).

In this paper we compare welfare effects in simple models of categorical unemployment benefits and universal basic income, with endogenous (voluntary) unemployment, in addition to some individuals who are unable to work at all. The first question is whether the unemployed are better off under UB than BI. The second question is to compare $\mathrm{UB}$ with $\mathrm{BI}$ in terms of the overall social welfare. 
Before examining our main model with only an extensive margin, we first consider the standard model of individually optimal labour supply, which allows both intensive and extensive margins. Using a simple, quasi-linear utility function with constant elasticity of labour supply but a general income distribution, we show that the unemployed are usually better off under BI than UB regardless of how strongly individual labour supply responds to wages and taxes. This indicates that the intensive margin of labour supply, though it often complicates the problem, does not dominate the extensive margin for UB and BI comparison.

Then we extend our analysis in our main model by allowing a general utility function, but restrict attention to the extensive margin or participation decision, in the spirit of Chone and Laroque (2005 and 2008). This restriction allows us to obtain strong and clear results, suggesting that, in contrast to the conventional wisdom, BI dominates UB in most plausible circumstances. Given any equilibrium unemployment level, lowering UB requires a higher tax rate and BI. It seems plausible that the net impact on the unemployed should depend on income distribution, the utility function and the level of unemployment. Surprisingly, however, this change always benefits the unemployed irrespective to all these factors. It reduces high net incomes, but always benefits lowerwage earners and even a majority of the population, provided the mean of population earnings is greater than the median, as is usually the case. Furthermore, lowering UB (with given unemployment and higher tax and $\mathrm{BI}$ ) is utilitarian welfare improving. Thus shifting transfers from UB to BI generally improves the efficiency of redistribution, and can be supported by a poor majority, though opposed by a minority of the richest. Finally, we can show that simultaneously reducing both unemployment and UB can benefit a 
majority of the employed population, as well as the unemployed, whatever their initial levels, thus offering potential political support even when the unemployed have only weak 'voice' in the process.

The plan of the paper is to describe the models in Section 2. Section 3 compares pure UB with pure BI given a simple utility function allowing both intensive and extensive margins. Then in section 4 we obtain our main results by evaluating a combination of UB and BI, given a general utility function but only extensive margins. We summarize our conclusions in section 5. All proofs are in the Appendix.

\section{The Models}

Throughout this paper we assume a frictionless labour market with voluntary unemployment and the total population is normalized to one. The government imposes a flat tax rate $t$ to finance UB for the unemployed and BI for everyone. If a person works, his income consists of after-tax earnings plus BI; if he does not work, his income is just BI plus UB. We consider two different models separately as described below.

(i)Model I: In this exemplary model, we assume a quasi-linear utility function, but allow individually optimal labour supply, with both extensive and intensive margins. A worker's productivity or type $w$ defines the hourly wage, distributed according to a distribution function $G(w)$ and associated density function $g(w)$ on $[\alpha, \beta]$, with $0 \leq \alpha<\beta$. If $\alpha=0$, these individuals have zero productivity, and are thus effectively disabled. We allow a possibly positive measure of such individuals.

Workers can choose working hours, $h$, and the disutility of work is equal to $h^{1+1 / \varepsilon} /(1+1 / \varepsilon)$, where $\varepsilon>0$, is the elasticity of labour supply. A household's overall 
utility is its income, which is consumed, minus the disutility of work. Given a flat tax $t$ and either a pure UB or a pure BI system, income consists of basic income $B$, plus aftertax earnings $w h(1-t)$ or unemployment benefit, $u$. We use this model to compare the two systems of UB and BI in terms of unemployed welfare. Our purpose is to show that regardless of how strongly individual labour supply responds to wages and taxes, BI is usually more desirable than UB. Given limited impacts of intensive margins, which is also consistent with empirical findings, we will proceed further to compare BI and UB only with extensive margins.

(ii) Model II: In this, our core model we allow a general utility function, but eliminate households' choice of working time, leaving them only the extensive margin or the participation decision. There is no intensive margin because jobs offer wage income and work requirements as a fixed package. The justification of this model comes from both empirical findings and our theoretical results using the first model. Hence earnings are defined per calendar time period, reflecting workers' productivity, denoted by $y$ and distributed on $[a, b]$, with $0 \leq a<b$, according to a distribution function $F(y)$ and a corresponding density function $f(y)$.

Since the level of work intensity is fixed by the contract, there is a required costly effort $e$ associated with employment, which includes the opportunity cost of time at work, such as 40 hours per week, while allowing for the non-pecuniary benefits. In many cases contracts for highly paid jobs require more hours and effort. On the other hand they also tend to offer better non-pecuniary benefits and job satisfaction. It is not always clear how the net disutility of work changes with income. Our simple assumption of a constant effort can be relaxed without substantial impact on the conclusions we obtain here. 
There is a flat tax, $t$, on earnings, to fund unemployment benefit $u$ conditional on not working, and basic income $B$, which is a transfer to all, independent of work status. In this case we allow any combination of BI and UB. A household's income is thus $y(1-t)$ plus $B$ if working, and $B+u$ if not working.

We assume that everyone has a utility function $V(m, e)$, where $m$ is income $\mathrm{e}^{3}$. It is continuously increasing, differentiable and concave in $m$, and decreasing in $e$. If an individual works, his utility is $V[y(1-t)+B, e]$. If he does not work, he receives $u$ and $B$, but makes no effort, so his utility is $V(u+B, 0)$. The assumption implies that given any tax rate $t$, there exits a marginal worker type with earnings $x$, such that all workers with higher earnings prefer employment, while $F(x)$, or those with lower earnings, choose not to work. The condition for this marginal worker $x$ to be indifferent between work or unemployment, can be expressed as:

$$
V[x(1-t)+B, e]=V(u+B, 0)
$$

We assume that the marginal worker's marginal utility of income is lower when she chooses to work than not work. This is reasonable, because she has more income when working and the marginal utility of income falls. Also, her marginal utility should be higher when not working since more time should allow more efficient consumption.

Given $x$, aggregate earnings or the economy's total output is $\int_{x}^{b} y f(y) d y$, denoted by $Y(x)$. The government budget constraint is then:

$$
t Y(x)=B+u F(x)
$$

\footnotetext{
${ }^{3}$ We can allow different utility functions for different productivity types, and still obtain our main results. But for a simple presentation, we restrict attention to the case of identical utility functions.
} 
When $x$ is fixed, we can choose the value of any one of three variables $t, B$ and $u$, and the other two will be determined by (1) and (2). In the following we will focus on how changes in $u$ affect the welfare of the unemployed and social welfare, so $t$ and $B$ become functions of $u$, which is then the government's only policy variable ${ }^{4}$. The additional choice of optimal $x$ is not considered here; it will obviously depend on government objectives and the wage distribution.

For simplicity we consider a flat tax only, but this assumption is not crucial. In the case of progressive taxes, we can separate the tax structure into two parts, one is the single tax rate $t$ applying to the lowest income band, and the other includes an additional marginal rate for high earners. The latter has no effect on the marginal worker since he only faces $t$, so (1) remains valid. The only change in (2) will be an extra term on the left hand side, representing extra tax revenue from additional tax rates. If we change $t$ but keep other tax rates constant, the extra term does not change and the impact on (2) is the same as before. Hence this modification will not change our main results obtained below.

\section{A Simple Utility and Flexible Hours}

In this section we use the first model introduced in section 2(i), allowing both intensive and extensive margins, and show that a pure BI system is likely to be superior to pure UB, with the Rawlsian goal of maximizing welfare of the unemployed. Intuitively, whether this is true should depend on how strongly the labour supply responds to taxes. However, we find this impact is quite limited, and transferring all tax

\footnotetext{
${ }^{4}$ The value of $u$ is not indexed to wages or earnings. Otherwise the tax rate would have little impact on the unemployment, as shown by Pissarides (1998).
} 
revenue to the unemployed actually makes them worse off compared with distributing (more) tax revenue to everyone equally.

In our model, a worker's utility $V=w h(1-t)+B-\frac{h^{1+1 / \varepsilon}}{1+1 / \varepsilon}$. His optimal hours maximizing $V$ are $[w(1-t)]^{\varepsilon}$, and the resulting utility is $B+\frac{w^{1+\varepsilon}}{1+\varepsilon}(1-t)^{1+\varepsilon}$. If he does not work, his utility is $u+B$. Hence he chooses to work if and only if $u<[w(1-t)]^{\varepsilon+1} /(1+\varepsilon)$. Clearly, when $u=0$, everyone with $w>0$ chooses to work, and there is no voluntary unemployment, except for those with $w=0$, who are permanently unemployed. But with unemployment benefit $u>0$, there will be voluntary unemployment if $\alpha$ is sufficiently small and the wage of the marginal employee $s$ is determined by

$$
u=\frac{s^{1+\varepsilon}}{1+\varepsilon}(1-t)^{1+\varepsilon}
$$

The corresponding unemployment rate is $F(s)$. Then total earnings or output are $\int_{s}^{\beta} w h g(w) d w=(1-t)^{\varepsilon} \int_{s}^{\beta} w^{1+\varepsilon} g(w) d w$. We denote $\int_{s}^{\beta} w^{1+\varepsilon} g(w) d w$ by $W(s)$. Thus the government budget constraint is:

$$
t(1-t)^{\varepsilon} W(s)=B+u F(s)
$$

We now compare the welfare of the unemployed under the two extreme cases of pure UB or pure $\mathrm{BI}^{5}$ We start with the UB case, where $u_{1}>0, B_{1}=0$, the marginal worker is denoted by $s_{1}$, and the unemployment rate is $F\left(s_{1}\right)$. The corresponding tax rate is $t_{1}$. We compare this situation with the $\mathrm{BI}$ case where $B_{2}>0, u_{2}=0$, all individuals with

\footnotetext{
${ }^{5}$ For simplicity we focus on two extreme cases to illustrate the relative unimportance of intensive margins. Allowing gradual changes between them does not alter our basic conclusions. In our second model with only extensive margins, we allow any infinitesimal changes.
} 
$w>0$ choose to work, and those with $w=0$ are always 'unemployed'. If $B_{2}>u_{1}$, those with $w=0$ must be better off after the change because they receive more income. The newly employed must be better off too since they are better off than those remaining unemployed. Thus all unemployed before the change are better off if $B_{2}>u_{1}$.

We can show that $B_{2}>u_{1}$ in plausible cases. In most economies the marginal workers earn low wages, compared with the average wage of the population. Given our definition, the average wage is equal to $\int_{\alpha}^{\beta} w g(w) d w$, denoted by $\bar{w}$. Thus we usually expect $s_{1}$ to be small relative to $\bar{w}$. If this is true, we can prove that $B_{2}>u_{1}$.

Proposition 1: All unemployed people under pure UB will be better off under pure BI if $s_{1}\left(1-t_{1}\right)<0.7 \bar{w}$.

Proof: see Appendix A.

The inequality in Proposition 1 is likely to hold. If $t_{1}=30 \%$, it reduces to $s_{1}<\bar{w}$, which is almost guaranteed as people with average productivity usually work. When $t_{1}$ is smaller, $s_{1}$ should also be lower, and the inequality is still likely to hold. For instance, when $t_{1}$ is close to 0 , the tax revenue is almost zero and $u_{1}$ must be very low. Hence $s_{1}$ should be nearly zero, and the inequality should hold. In any case the inequality must hold if $s_{1}<0.7 \bar{w}$, which merely requires that the marginal worker's wage to be lower than $70 \%$ of the average wage, again quite likely.

This result imposes no restriction on the elasticity of labor supply $\varepsilon$. It indicates that regardless of how strongly labour supply responds to tax, the unemployed are usually better off under the pure BI system, given any wage distribution. This is rather surprising. Moreover, by construction the BI system in our model eliminates all voluntary 
unemployment, and of course also the poverty trap. This contradicts the common and intuitive perception that to maintain or raise the welfare of the unemployed under BI, tax rates must increase so much that unemployment will also rise.

Since intensive margins have limited impacts on UB and BI comparison at least in our simple model, we shall ignore intensive margins, which are shown to be less important in empirical studies, but allow more general utility functions. In the next section we will focus on the extensive margin of labour supply and obtain stronger results for the superiority of BI over UB.

\section{Extensive Margin only}

In this section we use the model introduced in section 2(ii) and focus on the extensive margin. Instead of pure BI and UB, we allow any combination of them, and show that an increase in the former at the expense of the latter always benefits the poor, particularly the unemployed. It also raises utilitarian welfare. Moreover, such a change is beneficial to a poor majority, and consequently politically feasible. Finally, if earnings are finite, it may be a Pareto improvement as well.

We assume that the economy currently has a mixed system with $u_{1}>0$, marginal worker's earnings $x_{1}$ and unemployment rate $F\left(x_{1}\right)>0$. The change we consider is to lower $u$. Meanwhile we will adjust tax rate $t$ and basic income $B$ such that $x_{1}$, hence the unemployment rate $F\left(x_{1}\right)$, remain the same.

Given any fixed $x_{1}$, changes in $t$ and $B$ due to reducing $u$ can be solved from (1) and (2). We can show that, as $u$ falls, $B$ will rise by a larger amount (see Appendix B). From (2) we see that this implies $t$ also increases. Hence lowering UB while maintaining 
constant unemployment requires raising the tax rate and BI. As $B$ rises more than $u$ falls, $B+u$ must increase as $u$ falls, and we have a seemingly counter-intuitive result:

Proposition 2: For any given $x_{1}$, lowering $U B$, and hence raising tax and BI, always benefits the unemployed.

This means that the extra revenue from the higher tax is always more than sufficient to compensate for the extra cost of providing BI to the whole population. If our goal is to maximize the wellbeing of the unemployed, we can always do better by raising $\mathrm{BI}$ at the expense of $\mathrm{UB}$, until we reach a pure BI system. The most surprising point is that this conclusion does not depend on the type of utility function, income distribution or initial level of unemployment.

Since both $u_{1}$ and its change can be very small, our model does not require a discrete or significant jump or drop in UB. Indeed our conclusion holds for any magnitude of UB reduction from any initial level. The only major assumption is the absence of intensive margins. As we argued earlier, this does not seem to be very unrealistic, and as we showed in the previous section, the basic conclusion can still hold regardless of how strong intensive margins are.

In reality the Rawlsian objective may not entirely capture the purpose of the income redistribution. The government must take into account the potential negative impacts on others, rather than just benefits for the worst-off. So our next question is how UB reduction affects the employed and society as a whole. We can consider again a reduction of UB without changing the unemployment. If this change benefits those with low earnings and raises aggregate or utilitarian welfare, the adoption of BI will have more social justification. This is indeed the case (see Appendix $\mathrm{C}$ for the proof). 
Proposition 3: Given any $x_{1}, U B$ reduction always benefits low-income earners and raises utilitarian welfare.

Since unemployment and total output do not change, raising BI at expense of UB can be viewed as redistributing income from the rich to the poor without losing productive efficiency, and increasing utilitarian welfare. This seems socially desirable, except for likely opposition from the rich. Hence we need to investigate more precisely who benefits from lower UB and higher BI, and who do not. In particular we need to know their relative shares in the population.

Proposition 4: For any given $x_{1}, U B$ reduction benefits those with earnings less than $Y\left(x_{1}\right)+x_{1} F\left(x_{1}\right)$, but hurts those with earnings greater than $Y\left(x_{1}\right) /\left[1-F\left(x_{1}\right)\right]$.

Proof: see Appendix D.

We notice that $\left.Y\left(x_{1}\right) / 1-F\left(x_{1}\right)\right]$ is average earnings of the employed, and the expression $Y\left(x_{1}\right)+x_{1} F\left(x_{1}\right)$ is a kind of 'weighted' average earnings of the whole population, with all the weight for the unemployed given to the marginal worker $x_{1}$. So a person is worse off if he earns more than an average employee, while he is better off if he earns less than the weighted population average. If the initial unemployment is very low, i.e. $F\left(x_{1}\right)$ is close to zero, these two averages are very close, and the precise demarcation between the worse-off and better off is restricted to a small interval.

Our result suggests that lowering UB is likely to be supported by a majority of the population. We know $x_{1} F\left(x_{1}\right)+W\left(x_{1}\right)$ is higher than the average population earnings $W(a)$. Empirical data show that the average earnings are higher than the median in most economies. Hence the majority of the population is better off with a UB reduction. 
However, we are not sure if the majority of the working population supports a UB reduction. This ambiguity is due to the fact that we maintain the same unemployment, i.e. a fixed $x_{1}$. If we are not committed to this, we need not raise the tax so much as in the previous case, while lowering UB. This will reduce the income transfer to the unemployed, but increases employment, and imposes less damage on the rich. As long as we keep the unemployed indifferent, we can make most people better off. Thus we can maximize political support for the UB reduction. In particular, we will be able to lower unemployment and benefit a majority of the employed.

Proposition 5: Reducing both UB and unemployment can benefit everyone with earnings less than $Y\left(x_{1}\right) /\left[1-F\left(x_{1}\right)\right]$.

\section{Proof: see Appendix E.}

Since median earnings are usually lower than the mean, such a UB reduction will benefit the majority of the employed. This ensures political support even if the decision process excludes or gives low weight to the unemployed.

Finally, a natural question arises: how far can political support go, in other words, can a UB reduction be a Pareto improvement? If yes, we have the strongest argument to recommend such a reform for the welfare system. Not surprisingly, the general answer is negative. If there exist individuals with extremely high earnings, a tiny increase in tax will reduce their income so much that they cannot be fully compensated by an (relatively small) increase in BI. These individuals are definitely worse off.

Nevertheless, when earnings are bounded, the above argument may not apply. It is not impossible that a UB reduction benefits everyone. To demonstrate such a 
possibility, we again compare the two extreme cases: a pure UB system with $u_{1}>0$ and $B_{1}=0$ vs. a pure BI system with $u_{2}=0$ and $B_{2}>0$. Rather than keeping a fixed $x_{1}$, we allow unemployment to fall as in the case of Proposition 5, so we can minimize the tax increase, and reduce the burden on the rich. Meanwhile, to keep the unemployed indifferent for a UB reduction, $B_{2}$ should be equal to $u_{1}$. Then the change from a pure UB to a pure BI will be a Pareto improvement if the richest person is not worse off.

Since the richest worker has a utility $V[b(1-t)+B, e]$, he is better off if and only if $B_{2}>b\left(t_{2}-t_{1}\right)$. The budget constraint (2) with pure UB is $t_{1} Y\left(x_{1}\right)=u_{1} F\left(x_{1}\right)$, with pure BI it is $t_{2} Y\left(x_{2}\right)=B_{2}$. As $B_{2}=u_{1}$, the previous inequality becomes

$$
b\left\{\frac{1}{Y\left(x_{2}\right)}-\frac{F\left(x_{1}\right)}{Y\left(x_{1}\right)}\right\}<1
$$

(5) is the necessary and sufficient condition for a Pareto improvement. To show its potential validity, we consider a special case where $e=0$. In the real world most people prefer leisure to work, but also suffer psychologically from being unemployed. Our assumption holds if these two effects cancel each other out. Since there is no cost to work, no voluntary unemployment exists with pure BI, i.e., $x_{2}=a$. We assume the simplest uniform distribution $f(y)=1, a=0$ and $b=1$. Then we have $Y(a)=0.5, F\left(x_{1}\right)=$ $x_{1}$ and $Y\left(x_{1}\right)=0.5\left(1-x_{1}^{2}\right)$. One can check that (5) holds if and only if $x_{1}>\sqrt{2}-1$. Thus, switching from pure UB to pure BI is a Pareto improvement if and only if the initial unemployment rate is more than $41 \%$. This may not seem realistic, but we can interpret unemployment as 'non-employment' in a total population which may include a large number with very low productivity, so this indicates the possibility of a Pareto 
improvement if non-employment is high. Such a situation then provides the strongest case for eliminating UB.

\section{Conclusions}

In this paper we argue for the superiority of basic income to unemployment benefits. Our model with only extensive margins seems to be a reasonable approximation according to the empirical evidence. To justify our model, we first use a simple utility function to demonstrate that the unemployed are likely better off with pure BI than with pure UB, regardless of how strong the intensive margins are. With only an extensive margin our findings indicate superior welfare and efficiency properties of BI, which removes the 'poverty trap' effect of UB, provides more income to a given number of unemployed, leads to higher utilitarian welfare and benefits a poor majority. Moreover, allowing unemployment to fall, reducing UB and moving towards BI can benefit a majority of the employed, and potentially be a Pareto improvement.

To keep the model simple, we have neglected administrative cost-savings, and the non-pecuniary advantages of $\mathrm{BI}$, such as providing security and raising job quality for the less skilled, particularly when combined with a flat tax, which also implies significant savings in administrative costs and avoidance of incentive distortions, as widely discussed in the literature. Our results do not depend on the simplifying assumption of a flat tax, and a progressive tax may have advantages for redistribution, up to 'political' limits on top rates, which have to be balanced against additional administrative costs. The main conclusions are also robust to welfare dependence on relative income, in a broader framework of subjective wellbeing. Thus various generalizations might further strengthen 
the case for basic income, and perhaps also for a flat tax, and remain a challenge for future research.

\section{References}

Atkinson, A. B., Public Economics in Action: The Basic Income/Flat Tax Proposal, Clarendon Press, Oxford, 1995

Atkinson, A. B., 2002, "How Basic Income is Moving up the Policy Agenda: News from the Future", Paper presented at the 9th BIEN International Congress, 13 September 2002, Geneva (revised version).

Blundell, R. W., 1995, "The Impact of taxation on Labour Force Participation and Labour Supply", in OECD Job Study:Taxation, Employment and Unemployment, Chapter 3, Paris: OECD

Chone, P., and G. Laroque, 2005, "Optimal Incentives for Labour Force Participation", Journal of Public Economics, vol. 89(2-3), pp. 395-425.

Choné, P. and G. Laroque, 2008. "Optimal Taxation in the Extensive Model" IFS Working Papers, W08/08, Institute for Fiscal Studies.

Clark, C. and C. Kavanagh, 1996, "Basic Income, Inequality and Unemployment: Rethinking the Link between Work and Welfare", Journal of Economic Issues, vol. 30, pp. 399-406

Colombino, U., M. Locatelli, E. Narazani \& O’Donoghue, C. (2010) “Alternative basic income mechanisms: An evaluation exercise with a microeconometric model”. IZA DP No. 4781, Bonn.

Eissa, N. and J. Liebman, 1996, "Labor Supply Response to the Earned Income Tax Credit", Quarterly Journal of Economics, vol. 111, pp. 605-637.

Fitzpatrick, T., Freedom and Security: an Introduction to the Basic Income Debate, Palgrave Mcmillan, 1999,

Immervoll, H., H. Kleven, C. Kriener, \& Saez, E., 2007, "Welfare reform in European countries: A microsimulation analysis", Economic Journal, 117, no. 516, pp. 1-44.

Helliwell, J. F. and H. Huang, 2005, "How's the Job? Well-being and Social Capital in the Workplace", NBER Working Paper No. W11759

Kaplow, L., 2008, The Theory of Taxation and Public Economics, Princeton University Press

Mankiw, N. G., M. Weinzierl \& D. Yagan, 2009, "Optimal taxation in Theory and Practice", NBER Working Paper No. 15071

Offe, C., 2008, "Basic Income and the Labour Contract", Basic Income Studies, vol. 3, pp. 1-30.

Pissarides, C., 1998, "The Impact of Employment Tax Cuts on Unemployment and Wages, the Role of Unemployment Benefits and Tax Structure", European Economic Review, vol. 42, pp. $155-183$ 
Saez, E. (2002) "Optimal income transfer programs: intensive versus extensive labour supply Responses", Quarterly Journal of Economics, 117 (3), pp. 1039-1073.

Wilkinson, R. and K. Pickett, The Spirit Level, Allen Lane, London, 2009. 


\section{Appendix A: Proof of Proposition 1:}

Under pure $B I$, there is no unemployment, from (4) and the definition of $W(s)$ we get $B_{2}=$ $t_{2}\left(1-t_{2}\right)^{\varepsilon} W(\alpha)$. It is maximized when we choose $t_{2}=1 /(1+\varepsilon)$, so $B_{2}=\frac{\varepsilon^{\varepsilon}}{(1+\varepsilon)^{1+\varepsilon}} W(\alpha)$. Under pure $U B$ with $t_{1}$ and $s_{1}$, (3) implies $u_{1}=\frac{s_{1}^{1+\varepsilon}}{1+\varepsilon}\left(1-t_{1}\right)^{1+\varepsilon}$. So we have $B_{2}>u_{1}$ if

$$
\frac{\varepsilon^{\varepsilon}}{(1+\varepsilon)^{\varepsilon}} W(\alpha)>s_{1}^{1+\varepsilon}\left(1-t_{1}\right)^{1+\varepsilon}
$$

Since $W(\alpha)=\int_{\alpha}^{\beta} w^{1+\varepsilon} g(w) d w$ and $\bar{w}=\int_{\alpha}^{\beta} w g(w) d w$, Jensen's inequality implies $W(\alpha)>$ $\bar{w}^{1+\varepsilon}$. Hence a sufficient condition for (A.1) is $\frac{\varepsilon^{\varepsilon}}{(1+\varepsilon)^{\varepsilon}} \bar{w}^{1+\varepsilon}>s_{1}{ }^{1+\varepsilon}\left(1-t_{1}\right)^{1+\varepsilon}$, or

$$
\bar{w}\left(\frac{\varepsilon}{1+\varepsilon}\right)^{\frac{\varepsilon}{1+\varepsilon}}>s_{1}\left(1-t_{1}\right)
$$

When $1+1 / \varepsilon=e$, the left hand side of (A.2) reaches its minimum, which is $0.7 \bar{w}$. Hence we have $B_{2}>u_{1}$ if $0.7 \bar{w}>s_{1}\left(1-t_{1}\right)$.

\section{Appendix B: Proof of Proposition 2:}

Given $x_{1}$, we differentiate (1) and (2) with respect to $u$, and obtain:

$$
\begin{aligned}
& \left\{\frac{d B}{d u}-x_{1} \frac{d t}{d u}\right\} V_{1}\left[x_{1}(1-t)+B, e\right]=\left\{1+\frac{d B}{d u}\right\} V_{1}(u+B, 0), \\
& \frac{d t}{d u} Y\left(x_{1}\right)=\frac{d B}{d u}+F\left(x_{1}\right)
\end{aligned}
$$

$V_{1}$ denotes the partial derivative with respect to income. Solving (B.1) and (B.2) we get

$$
\frac{d B}{d u}=-\frac{Y\left(x_{1}\right) V_{1}(u+B, 0)+x_{1} F\left(x_{1}\right) V_{1}\left[x_{1}(1-t)+B, e\right]}{Y\left(x_{1}\right) V_{1}(u+B, 0)+\left[x_{1}-Y\left(x_{1}\right)\right] V_{1}\left[x_{1}(1-t)+B, e\right]}
$$

Since $Y\left(x_{1}\right)>x_{1}\left[1-F\left(x_{1}\right)\right]$, we have $x_{1} F\left(x_{1}\right)>x_{1}-Y\left(x_{1}\right)$. So $\frac{d B}{d u}<-1$. 


\section{Appendix C: Proof of Proposition 3:}

Let $B_{2}$ and $t_{2}$ be the $\mathrm{BI}$ and tax rate after the UB reduction. From our earlier result, we know that $B_{2}>B_{1}$ and $t_{2}>t_{1}$. Given any $x_{1}$, lowering $u$ benefits an employee with earnings $y$ if and only if $y\left(1-t_{2}\right)+B_{2}>y\left(1-t_{1}\right)+B_{1}$, or $y<\frac{B_{2}-B_{1}}{t_{2}-t_{1}}$.

Since $x_{1}$ is fixed, the change in $u$ does not affect the total output, and merely redistributes it from the rich to the poor, without altering the ranking of their net income. Given our assumption, the unemployed and the low-income earners have higher marginal utility of income. Hence such income redistribution must raise the total welfare.

\section{Appendix D: Proof of Proposition 4:}

(i) We first show that a worker $y$ is better of, i.e. $B_{2}-B_{1}>y\left(t_{2}-t_{1}\right)$ if $y \leq Y\left(x_{1}\right)+x_{1} F\left(x_{1}\right)$. We let $u_{1}$ and $u_{2}$ be the value of UB before and after its reduction. The marginal worker's corresponding indifference conditions are:

$$
\begin{aligned}
& V\left[x_{1}\left(1-t_{1}\right)+B_{1}, e\right]=V\left(u_{1}+B_{1}, e\right) \\
& V\left[x_{1}\left(1-t_{2}\right)+B_{2}, e\right]=V\left(u_{2}+B_{2}, e\right)
\end{aligned}
$$

Proposition 2 implies $u_{2}+B_{2}>u_{1}+B_{1}$. We assume that a worker's marginal utility of income is lower when he works. Hence the income difference on the left hand side of (D.1) must be larger than that on the right hand side, i.e., $x_{1}\left(1-t_{2}\right)+B_{2}-x_{1}\left(1-t_{1}\right)-B_{1}$ $>u_{2}+B_{2}-u_{1}-B_{1}$, or $t_{2}-t_{1}<\left(u_{1}-u_{2}\right) / x_{1}$.

From (2) we get $u_{\mathrm{i}}=\left[t_{\mathrm{i}} Y\left(x_{1}\right)-B_{\mathrm{i}}\right] / F\left(x_{1}\right)$, so $u_{1}-u_{2}=\left[B_{2}-B_{1}+t_{1} Y\left(x_{1}\right)-t_{2} Y\left(x_{1}\right)\right] / F\left(x_{1}\right)$. So

$$
t_{2}-t_{1}<\frac{B_{2}-B_{1}+\left(t_{1}-t_{2}\right) Y\left(x_{1}\right)}{x_{1} F\left(x_{1}\right)}
$$

(D.2) implies $B_{2}-B_{1}>\left(t_{2}-t_{1}\right)\left[Y\left(x_{1}\right)+x_{1} F\left(x_{1}\right)\right]$. If $y<Y\left(x_{1}\right)+x_{1} F\left(x_{1}\right), B_{2}-B_{1}>y\left(t_{2}-t_{1}\right)$.

(ii) We then show $B_{2}-B_{1}<y\left(t_{2}-t_{1}\right)$ when $y \geq Y\left(x_{1}\right) /\left[1-F\left(x_{1}\right)\right]$. 
Since $u_{2}+B_{2}>u_{1}+B_{1}$ and $u_{1}-u_{2}=\left[B_{2}-B_{1}+t_{1} Y\left(x_{1}\right)-t_{2} Y\left(x_{1}\right)\right] / F\left(x_{1}\right)$, we have $B_{2}-B_{1}>$ $\left[\left(t_{1}-t_{2}\right) Y\left(x_{1}\right)+B_{2}-B_{1}\right] / F\left(x_{1}\right)$, which implies $B_{2}-B_{1}<\frac{\left(t_{2}-t_{1}\right) Y\left(x_{1}\right)}{1-F\left(x_{1}\right)}$.

Hence we have $B_{2}-B_{1}<y\left(t_{2}-t_{1}\right)$ if $y \geq Y\left(x_{1}\right) /\left[1-F\left(x_{1}\right)\right]$.

\section{Appendix E: Proof of Proposition 5:}

Now we allow $x_{1}$ to fall to $x_{2}$, while lowering $u$, i.e. we have $u_{2}<u_{1}, x_{2}<x_{1}, B_{2}>B_{1}$, and $t_{2}>t_{1}$. To minimize the number of worse-off high-income earners by the UB reduction, we keep the unemployed indifferent, i.e. $u_{2}+B_{2}=u_{1}+B_{1}$. We now show that $B_{2}-B_{1}>$ $y\left(t_{2}-t_{1}\right)$ for any $y<Y\left(x_{1}\right) /\left[1-F\left(x_{1}\right)\right]$. As (2) implies $B_{\mathrm{i}}=t_{\mathrm{i}} Y\left(x_{\mathrm{i}}\right)-F\left(x_{\mathrm{i}}\right) u_{\mathrm{i}}$, we have

$$
B_{2}-B_{1}=t_{2} Y\left(x_{2}\right)-t_{1} Y\left(x_{1}\right)+F\left(x_{1}\right) u_{1}-F\left(x_{2}\right) u_{2}
$$

Since $x_{2}<x_{1}$, we get $F\left(x_{2}\right)<F\left(x_{1}\right)$. So $B_{2}-B_{1}>t_{2} Y\left(x_{2}\right)-t_{1} Y\left(x_{1}\right)+F\left(x_{1}\right)\left(u_{1}-u_{2}\right)$. But $u_{1}-$ $u_{2}=B_{2}-B_{1}$, so $B_{2}-B_{1}>\left[t_{2} Y\left(x_{2}\right)-t_{1} Y\left(x_{1}\right)\right] /\left[1-F\left(x_{1}\right)\right]$. Hence $B_{2}-B_{1}>y\left(t_{2}-t_{1}\right)$ if

$$
\frac{t_{2} Y\left(x_{2}\right)-t_{1} Y\left(x_{1}\right)}{1-F(x)}>y\left(t_{2}-t_{1}\right)
$$

When $y<Y\left(x_{1}\right) /\left[1-F\left(x_{1}\right)\right]$, (E.2) holds if $Y\left(x_{2}\right)>Y\left(x_{1}\right)$, which is guaranteed as $x_{2}<x_{1}$. 